\title{
A novel quinone-based polymer electrode for high performance lithium-ion batteries
}

\author{
Jian Xie ${ }^{1}$, Zilong Wang ${ }^{1}$, Peiyang $\mathrm{Gu}^{1}$, Yi Zhao ${ }^{1}$, Zhichuan J. Xu${ }^{1}$ and Qichun Zhang ${ }^{1,2^{*}}$
}

\begin{abstract}
Designing of high electrochemical performance organic electrode materials has attracted tremendous attention. Recent investigations revealed that quinone-based polymers along with the stable thioether bonds could achieve a high specific capacity and a good cycling stability simultaneously. In this study, we synthesized a novel ladder-structured polymer poly(2,3-dithiino-1,4- benzoquinone) (PDB) through a simple two-step polymerization. The electrochemical performance indicated that PDB could achieve a high reversible specific capacity of $681 \mathrm{mAh} \mathrm{g}^{-1}$ with $98.4 \%$ capacity retention after 100 cycles. A good rate performance was also achieved with a fast recovery of the capacity after testing at different current densities. Ultra-long cycling performance of PDB was also investigated. The promising results of PDB provided us more confidence to continue searching for high performance polymers through the modification of organic structures.
\end{abstract}

Keywords lithium battery, electrode, polymer, carbonyl, thioether

The invention of lithium-ion battery (LIB) has brought huge convenience in our daily life. Owing to LIB's light weight, high specific capacity and long cycling stability, successful investigations have been devoted to the applications for portable devices and electric vehicles [1,2]. However, due to the large-scale industrial production of the transition metal-based electrode materials, more and more toxic and non-renewable chemical wastes have been created [3]. Recently, new strategies including the designing of binder-free and composite electrode materials have been proposed [4-6]. Moreover, to search for potential greener electrode materials, organic compounds have attracted a lot of attention [1,7-9]. Although many small molecules have been synthesized and investigated as the electrode materials for LIBs, the reported electrochemical performances in terms of both specific capacity and cycling stability were still far away from the practical applications due to the serious dissolution issue [10-12]. Therefore, it is urgent to design novel organic compounds that can overcome the dissolution issue without sacrificing the electrochemical performance.

In the past two decades, several strategies have been comprehensively proposed and evaluated. For example, one of the earliest attempts was through the synthesis of lithium salts $[8,9,13-15]$, which delivered relatively better cycling stability and specific capacity compared with the previously reported small molecules. It was reported that $\mathrm{Li}_{2} \mathrm{C}_{8} \mathrm{H}_{4} \mathrm{O}_{4}$ (Li terephthalate) could accept two lithium ions to give an initial reversible capacity of $300 \mathrm{mAh} \mathrm{g}^{-1}$ at $1 \mathrm{C}$ [9]. In addition, all-organic LIBs fabricated by the tetralithium salt of 2,3,5,6-tetrahydroxy-1,4-benzoquinone $\left(\mathrm{Li}_{4} \mathrm{C}_{6} \mathrm{O}_{6}, \mathrm{THQ}\right)$ and the tetralithium salt of 2,5-dihydroxyterephthalic acid $\left(\mathrm{Li}_{4} \mathrm{C}_{8} \mathrm{H}_{2} \mathrm{O}_{6}, \mathrm{Li}_{4} \mathrm{DHTPA}\right)$ were evaluated respectively $[8,14]$. The cells were able to provide reversible capacities of 120 and $200 \mathrm{mAh} \mathrm{g}^{-1}$ after 50 cycles and 20 cycles, separately at low current densities. Although these organic salts displayed better electrochemical performances as compared with the old-designed organic molecules, the cycling ability of them was still not stable and the specific capacities were still low as compared with the inorganic electrode materials. From the perspective of molecular design, another strategy is to increase the molecular weight of organic compounds by polymerization [16]. Especially, these polymers with large conjugated structures are not easily dissolved into the electrolytes. Nevertheless, increasing the molecular weight through polymerization could only somewhat resolve the dissolution issue. More importantly, the specific capacity of the larger structures will decrease accordingly.

Hence, in order to achieve a compromising result between the cycling stability and the specific capacity, our strategy is to develop quinone-based rigid backbone polymers with the chemically stable thianthrene structures. Recently, polymers containing redox-active carbonyl groups $(\mathrm{C}=\mathrm{O})$ have been thoroughly investigated [12,17-27]. Especially, quinones are regarded as the most promising types

\footnotetext{
School of Materials Science and Engineering, Nanyang Technological University, Singapore 639798, Singapore

${ }^{2}$ Division of Chemistry and Biological Chemistry, School of Physical and Mathematics Science, Nanyang Technological University, Singapore 637371, Singapore

Corresponding author (email: qczhang@ntu.edu.sg)
} 
of organic electrode materials $[12,18,20,21,23,24]$. The redox mechanism of the electrochemically reactive carbonyl groups is well explained by the enolation process between the lithium ions and the carbonyl groups. Further investigations found that each $\mathrm{C}_{6}$ ring can reversibly accept six lithium ions to form a $\mathrm{Li}_{6} / \mathrm{C}_{6}$ complex $[17,28]$. The results were supported by both the experimental and calculation studies. It was found that polymers with the thioether bonds (C-S-C), which do not undergo bond cleavage during the redox reactions, could behave more stable as compared with those with disulfide bonds [23]. Additionally, the thioether bond could provide fast electron transfer caused by the $\pi$-electron delocalization between the lone pair of sulfur and the quinonyl rings [26]. A sulfide polymer was synthesized based on 3,4,9,10-perylenetetracarboxylic dianhydride (PTCDA) [26]. Apart from the carbonyl bonds that provided the reactive centers for the redox reactions, the thioether bonds was found to greatly enhance the conductivity of the electrode and thus leaded to a high stability of the electrode. More recently, polyanthraquinone (PAQ) and lithium salt of poly(2,5-dihydroxy- $p$-benzoquinonyl sulfide) ( $\mathrm{Li}_{2} \mathrm{PDHBQS}$ ) were also discovered to have the ability to deliver excellent cycling stability after ultra-long charge-discharge cycles $[18,20]$. The extraordinary electrochemical results of these polymers indicated that quinone-based polymers with the thioether bond could effectively improve the redox reactivity as well as prevent the unwanted dissolution of the organic compounds.

Combining the merits of quinone-based polymers, herein, we report a novel ladder-structured polymer poly (2,3-dithiino-1,4-benzoquinone) (PDB), which showed excellent electrochemical performance in terms of specific capacity (initial reversible capacity, $1050 \mathrm{mAh} \mathrm{g}^{-1}$ ), cycling stability (100 cycles at $0.1 \mathrm{~A} \mathrm{~g}^{-1}$ and 1000 cycles at $2 \mathrm{~A} \mathrm{~g}^{-1}$ ) and rate capability $\left(0.1\right.$ to $4.2 \mathrm{~A} \mathrm{~g}^{-1}$ ). The polymer sample was synthesized through a simple two-step polymerization between 2,3,5,6-tetrafluorocyclohexa-2,5-diene-1,4-dione and $\mathrm{Na}_{2} \mathrm{~S} \cdot 9 \mathrm{H}_{2} \mathrm{O}$ at $80^{\circ} \mathrm{C}$ (Scheme 1).

Field-emission scanning electron microscopy (FESEM) was performed on JEOL/JSM-6340F at $5 \mathrm{kV}$ to characterize the morphology of PDB. Fig. 1 shows that the diameters of the polymer particles are in the range of $500 \mathrm{~nm}$ to $1 \mu \mathrm{m}$. Compared with those bigger-sized polymers, the micro-sized PDB with larger surface areas would be able to promote an enhanced connection between the polymer particles and the carbon nanotubes (CNTs), and hence results in an improved conductivity of the electrode material.

The chemical structure of the as-prepared sample was characterized by Fourier transform infrared spectroscopy (FTIR). As shown in Fig. 2a, the strong absorption band near $1630 \mathrm{~cm}^{-1}$ corresponds to the stretching vibration of the carbonyl group $(\mathrm{C}=\mathrm{O})$ [23]. The peaks at 1423, 1382, 1176 and $1089 \mathrm{~cm}^{-1}$ can be assigned to the carbon sulfur bond (C-S) [12,23,26,29,30], indicating the successful for-

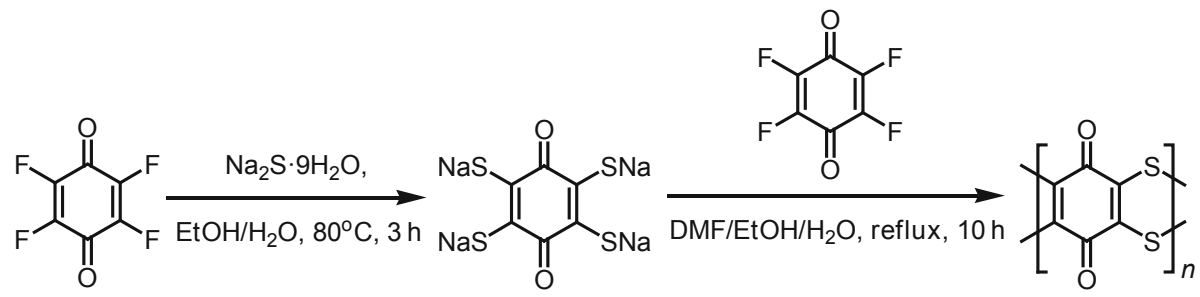

Scheme 1 The synthesis route of PDB.
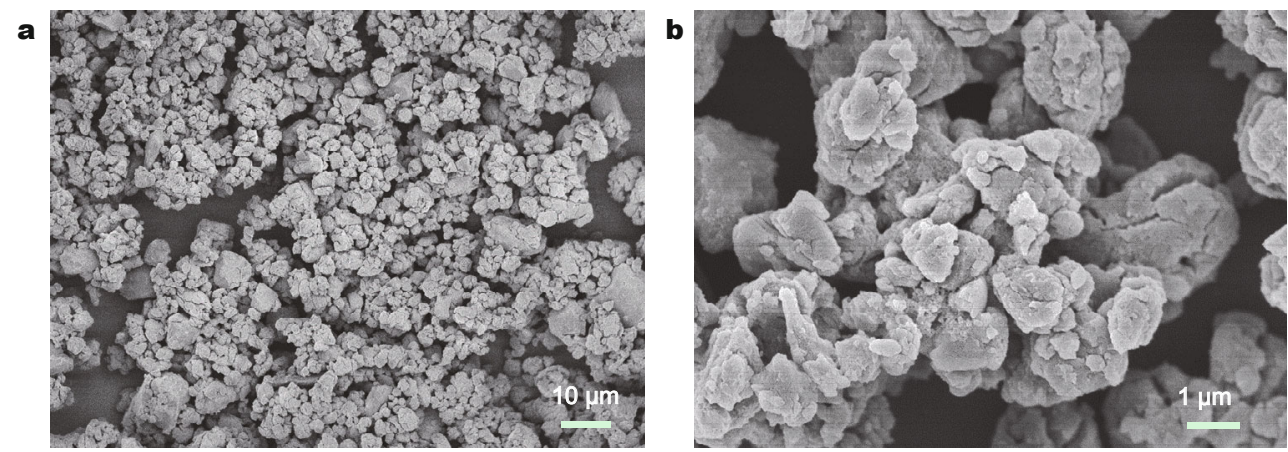

Figure 1 FESEM images of PDB micro-particles: (a) low-resolution image, (b) high-resolution image. 

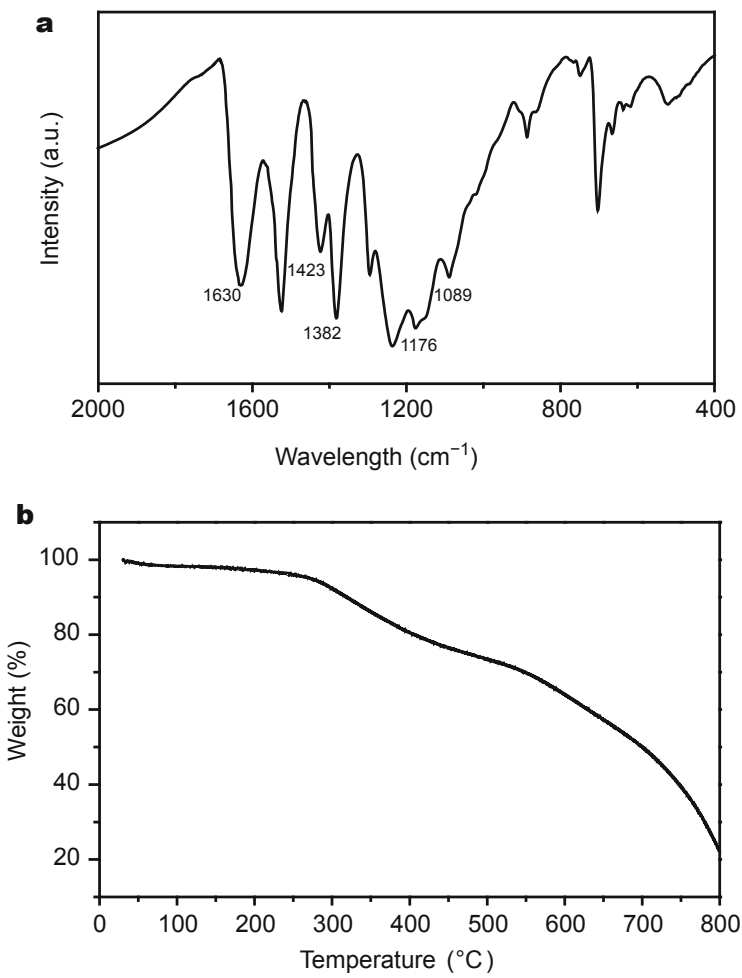

Figure 2 (a) FTIR spectra of PDB and (b) TGA curve of PDB in nitrogen

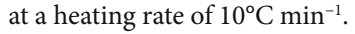

mation of the thioether bond $(\mathrm{C}-\mathrm{S}-\mathrm{C})$ during the polymerization process. To further evaluate the thermal property of PDB. Thermogravimetric analysis (TGA) was conducted under nitrogen atmosphere between room temperature and $800^{\circ} \mathrm{C}$. As shown in Fig. 2b, the decomposition of PDB starts at approximately $300^{\circ} \mathrm{C}$, followed by another weight loss at around $500^{\circ} \mathrm{C}$. This two-step weight loss could be due to the incomplete polymerization of the polymer sample. Therefore, the molecules with relatively smaller molecular weight decompose faster than the completely polymerized molecules. Nevertheless, the onset decomposition temperature of $300^{\circ} \mathrm{C}$, which is consistent with majority of the polymers, still suggests a good thermal stability of PDB.

In order to evaluate the electrochemical performances of the PDB electrode, the active material (80 wt.\%) was mixed with 10 wt.\% CNTs and 10 wt.\% polyvinylidene fluoride (PVDF) in N-methyl-2-pyrrolidone (NMP) solvent. Various measurements were carried out, including cyclic voltammetry (CV), galvanostatic charge-discharge profiles, rate performance and long-term cycling. Fig. 3a shows the CV curves of the initial three cycles between 3.0 and $0.0 \mathrm{~V}$ at a scanning rate of $0.2 \mathrm{mV} \mathrm{s}^{-1}$. Obviously, there are some differences between the first cycle and the following cycles, especially during the lithiation process.
For the first cathodic scan, the large broad peak below 1.04 $\mathrm{V}$ is associated with the lithiation process occurred on the carbons of the $\mathrm{C}_{6}$ rings along with the formation of a solid electrolyte interphase (SEI) film [17,28]. On the reverse anodic scan, a corresponding peak near $1.05 \mathrm{~V}$ is attributed to the delithiation process [17]. For the second and the third scans, the peak in the range of $2.25-2.5 \mathrm{~V}$ during the anodic scan is associated with the enolation process, which can be attributed to the reoxidation of the lithium enolate to form the carbonyl group $[23,26]$. It can be observed that, the CV curves of the $2^{\text {nd }}$ and $3^{\text {rd }}$ cycles almost overlapped, indicating the good stability of PDB during the electrochemical process.

The galvanostatic charge-discharge process was performed between the potential of 0.01 and $3.0 \mathrm{~V}$ at a current density of $100 \mathrm{mAh} \mathrm{g}^{-1}$. The charge-discharge profiles of the $1^{\text {st }}, 2^{\text {nd }}, 3^{\text {rd }}, 10^{\text {th }}$ and $100^{\text {th }}$ cycles are displayed in Fig. $3 \mathrm{~b}$. It can be observed that PDB delivered an initial discharge capacity of $1614 \mathrm{mAh} \mathrm{g}^{-1}$ and a high reversible capacity of $1050 \mathrm{mAh} \mathrm{g}^{-1}$ in the subsequent charge process, corresponding to a Coulombic efficiency of $65.1 \%$. The loss of $564 \mathrm{mAh} \mathrm{g}^{-1}$ is attributed to the irreversible capacities from the formation of the SEI film, which can also be detected from the CV curves. It is widely known that the formation of the SEI film is a very common phenomenon for the anode materials during the initial discharge process [31,32]. Even though, the initial reversible capacity is much better than most of the thioether or thianthrene bond-containing compounds [20,33-36], indicating a superiority of PDB over them. Additionally, the potential plateaus observed in the charge-discharge profiles show good consistent with the redox peaks in the CV curves.

As shown in Fig. 3c, the rate capability of the sample was further examined at different current densities including $0.1,0.2,0.5,1.0$ and $4.2 \mathrm{~A} \mathrm{~g}^{-1}$. Each current density corresponds to five cycles of charge and discharge processes. The results indicate that $\mathrm{PDB}$ could deliver reversible capacities of 887, 692, 500, 357 and $107 \mathrm{mAh} \mathrm{g}^{-1}$, respectively, at different current densities mentioned above. It is worthy to note that, a high reversible capacity of $748 \mathrm{mAh} \mathrm{g}^{-1}$ could still be achieved when the current density returned back to $0.1 \mathrm{~A} \mathrm{~g}^{-1}$. This reversible capacity of $748 \mathrm{mAh} \mathrm{g}^{-1}$ was quite consistent with the reversible capacity of $793 \mathrm{mAh} \mathrm{g}^{-1}$ at the same cycle during the charge and discharge process at $100 \mathrm{~mA} \mathrm{~g}^{-1}$, indicating a good repeatability and an excellent structure stability of the PDB electrode material.

To investigate the cycling stability of PDB, specific capacity vs. cycle number was plotted as shown in Fig. $3 \mathrm{~d}$. It can be seen that, even after 100 cycles, PDB could still

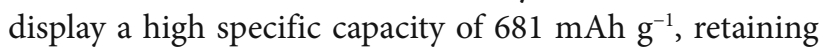



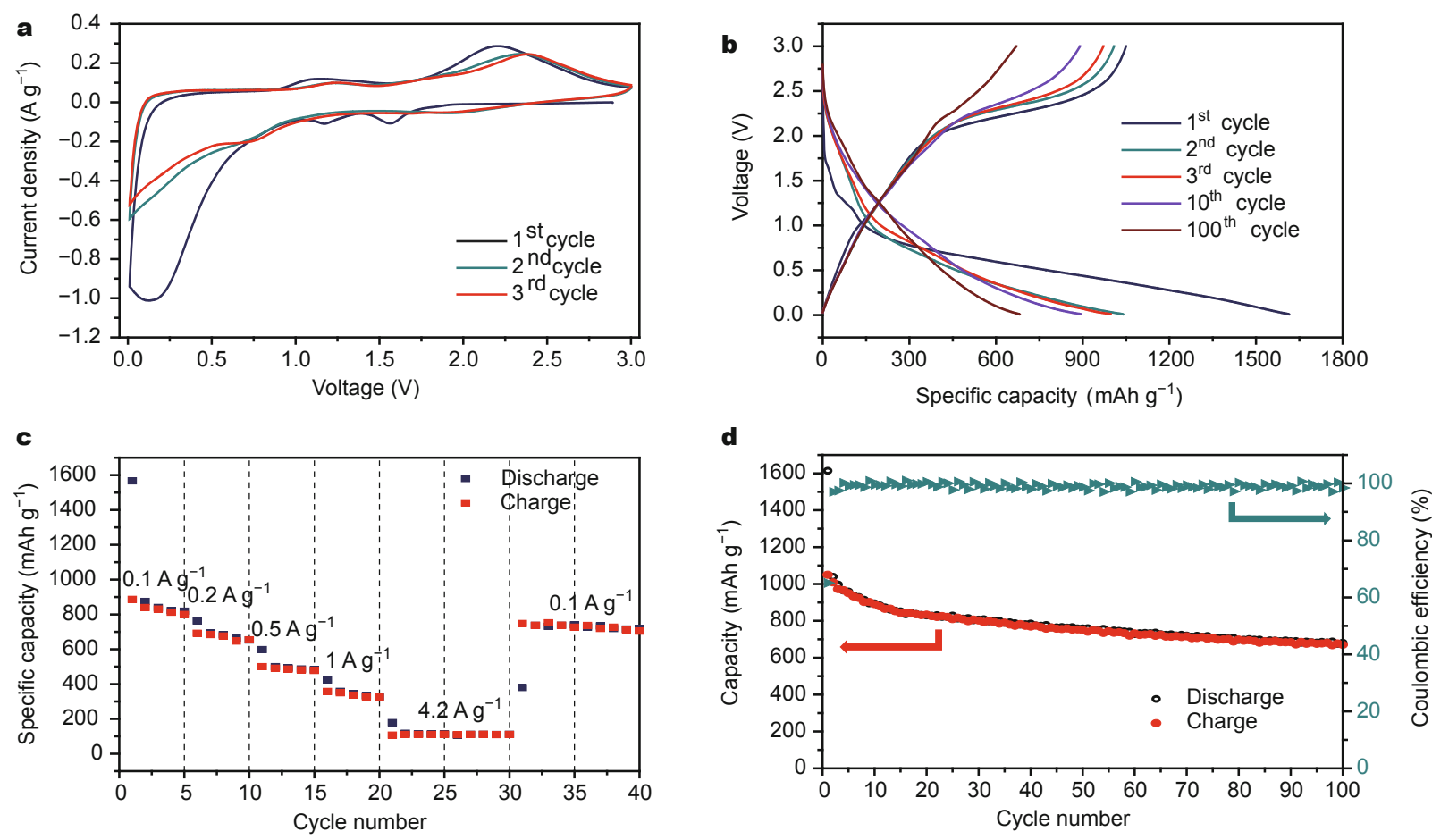

Figure 3 (a) CV curves of PDB at a scan rate of $0.2 \mathrm{mV} \mathrm{s}^{-1}$. (b) Galvanostatic charge-discharge profiles of PDB at a current density of $100 \mathrm{~mA} \mathrm{~g}^{-1}$. (c) Rate performance of PDB at different current densities. (d) Cycling performance and Coulombic efficiency of PDB at a current density of $100 \mathrm{~mA} \mathrm{~g}^{-1}$.

$71 \%$ of its specific capacity as compared with its $5^{\text {th }}$ cycle. This good specific capacity is among the best performances of pure organic electrode materials that have been reported so far. Moreover, apart from the first cycle, the average Coulombic efficiency of each cycle (the $1^{\text {st }}$ cycle excluded) is as high as $99.1 \%$, further confirming the good stability of PDB. Fig. S1 shows the ultra-long cycling capability of the sample. The reversible specific capacity of PDB was maintained at $161 \mathrm{mAh} \mathrm{g}^{-1}$ after 1000 cycles at a high current density of $2 \mathrm{~A} \mathrm{~g} \mathrm{~g}^{-1}$. Although the result suggests a moderate specific capacity of PDB at high current density, the performance is still better than those of majority of the reported lithium salt anode materials for LIBs [37].

In conclusion, we have developed a novel polymer PDB that can be used as the electrode material for LIBs. For the characterizations of PDB, FTIR result indicates the successful formation of the thioether bond and TGA shows a good thermal stability of PDB at high temperatures. The electrochemical performance reveals that $\mathrm{PDB}$ possesses a high initial reversible capacity of $1050 \mathrm{mAh} \mathrm{g}^{-1}$ and still maintains a reversible capacity of $681 \mathrm{mAh} \mathrm{g}^{-1}$ after 100 cycles. Additionally, the good rate performance and the ultra-long cycling capability suggest the good stability of PDB. Our results show that carbonyl and thioether bonds containing polymers are promising high performance can- didates as organic electrode materials for LIBs. Utilizing the advantages of carbonyl and thioether bonds, we are continuing searching for potential high performance organic electrodes through designing and modification of organic structures.

Received 21 December 2015; accepted 3 January 2016; published online 8 January 2016

1 Armand M, Tarascon JM. Building better batteries. Nature, 2008, 451: 652-657

2 Tarascon JM. Key challenges in future Li-battery research. Phil Trans R Soc A, 2010, 368: 3227-3241

3 Poizot P, Dolhem F. Clean energy new deal for a sustainable world: from non- $\mathrm{CO}_{2}$ generating energy sources to greener electrochemical storage devices. Energy Environ Sci, 2011, 4: 2003-2019

4 Wang ZL, Xu D, Wang HG, Wu Z, Zhang XB. In situ fabrication of porous graphene electrodes for high-performance energy storage. ACS Nano, 2013, 7: 2422-2430

5 Huang XL, Wang RZ, Xu D, et al. Homogeneous CoO on graphene for binder-free and ultralong-life lithium ion batteries. Adv Funct Mater, 2013, 23: 4345-4353

6 Huang XL, Xu D, Yuan S, et al. Dendritic Ni-P-coated melamine foam for a lightweight, low-cost, and amphipathic three-dimensional current collector for binder-free electrodes. Adv Mater, 2014, 26: 7264-7270

7 Song Z, Zhou H. Towards sustainable and versatile energy storage devices: an overview of organic electrode materials. Energy Environ Sci, 2013, 6: 2280-2301

8 Chen H, Armand M, Courty M, et al. Lithium salt of tetrahydroxy- 
benzoquinone: toward the development of a sustainable Li-ion battery. J Am Chem Soc, 2009, 131: 8984-8988

9 Armand M, Grugeon S, Vezin H, et al. Conjugated dicarboxylate anodes for Li-ion batteries. Nat Mater, 2009, 8: 120-125

10 Liang Y, Zhang P, Chen J. Function-oriented design of conjugated carbonyl compound electrodes for high energy lithium batteries. Chem Sci, 2013, 4: 1330-1337

11 Geng J, Bonnet JP, Renault S, Dolhemb F, Poizot P. Evaluation of polyketones with $\mathrm{N}$-cyclic structure as electrode material for electrochemical energy storage: case of tetraketopiperazine unit. Energy Environ Sci, 2010, 3: 1929-1933

12 Song Z, Zhan H, Zhou Y. Anthraquinone based polymer as high performance cathode material for rechargeable lithium batteries. Chem Commun, 2009, 448-450

13 Luo C, Huang R, Kevorkyants R, et al. Self-assembled organic nanowires for high power density lithium ion batteries. Nano Lett, 2014, 14: 1596-1602

14 Wu J, Rui X, Long G, et al. Pushing up lithium storage through nanostructured polyazaacene analogues as anode. Angew Chem Int Ed, 2015, 54: 7354-7358

15 Renault S, Gottis S, Barrès AL, et al. A green Li-organic battery working as a fuel cell in case of emergency. Energy Environ Sci, 2013, 6: 2124-2133

16 Liang Y, Tao Z, Chen J. Organic electrode materials for rechargeable lithium batteries. Adv Energy Mater, 2012, 2: 742-769

17 Wu J, Rui X, Wang C, et al. Nanostructured conjugated ladder polymers for stable and fast lithium storage anodes with high-capacity. Adv Energy Mater, 2015, 5: 1402189

18 Song Z, Qian Y, Gordin ML, et al. Polyanthraquinone as a reliable organic electrode for stable and fast lithium storage. Angew Chem Int Ed, 2015, 127: 14153-14157

19 Wang HG, Yuan S, Ma DL, et al. Tailored aromatic carbonyl derivative polyimides for high-power and long-cycle sodium-organic batteries. Adv Energy Mater, 2014, 4: 1301651

20 Song Z, Qian Y, Liu X, et al. A quinone-based oligomeric lithium salt for superior Li-organic batteries. Energy Environ Sci, 2014, 7: 4077-4086

21 Song Z, Xu T, Gordin ML, et al. Polymer-graphene nanocomposites as ultrafast-charge and -discharge cathodes for rechargeable lithium batteries. Nano Lett, 2012, 12: 2205-2211

22 Nokami T, Matsuo T, Inatomi Y, et al. Polymer-bound pyrene4,5,9,10-tetraone for fast-charge and -discharge lithium-ion batteries with high capacity. J Am Chem Soc, 2012, 134: 19694-19700

23 Liu K, Zheng J, Zhong G, Yang Y. Poly(2,5-dihydroxy-1,4-benzoquinonyl sulfide) (PDBS) as a cathode material for lithium ion batteries. J Mater Chem, 2011, 21: 4125-4131

24 Choi W, Harada D, Oyaizu K, Nishide H. Aqueous electrochemistry of poly(vinylanthraquinone) for anode-active materials in high-density and rechargeable polymer/air batteries. J Am Chem Soc, 2011, 133: 19839-19843

25 Song Z, Zhan H, Zhou Y. Polyimides: promising energy-storage materials. Angew Chem Int Ed, 2010, 49: 8444-8448

26 Han X, Chang C, Yuan L, Sun J. Aromatic carbonyl derivative poly- mers as high-performance Li-ion storage materials. Adv Mater, 2007, 19: 1616-1621

27 Wang HG, Yuan S, Si Z, Zhang XB. Multi-ring aromatic carbonyl compounds enabling high capacity and stable performance of sodium-organic batteries. Energy Environ Sci, 2015, 8: 3160-3165

28 Han X, Qing G, Sun J, Sun T. How many lithium ions can be inserted onto fused $\mathrm{C}_{6}$ aromatic ring systems? Angew Chem Int Ed, 2012, 51: $5147-5151$

$29 \mathrm{Xu}$ W, Read A, Koech PK, et al. Factors affecting the battery performance of anthraquinone-based organic cathode materials. J Mater Chem, 2012, 22: 4032-4039

30 Ai W, Xie L, Du Z, et al. A novel graphene-polysulfide anode material for high-performance lithium-ion batteries. Sci Rep, 2013, 3: 2341

31 Soto FA, Ma Y, de la Hoz JMM, Seminario JM, Balbuena PB. Formation and growth mechanisms of solid-electrolyte interphase layers in rechargeable batteries. Chem Mater, 2015, 27: 7990-8000

32 Lu P, Li C, Schneider EW, Harris SJ. Chemistry, impedance, and morphology evolution in solid electrolyte interphase films during formation in lithium ion batteries. J Phys Chem C, 2014, 118: 896903

33 Speer ME, Kolek M, Jassoy JJ, et al. Thianthrene-functionalized polynorbornenes as high-voltage materials for organic cathode-based dual-ion batteries. Chem Commun, 2015, 51: 1526115264

34 Sakata J. A battery with variable electrostatic capacity controlled by redox reaction. J Power Sources, 2012, 203: 184-189

35 Lee DY, Lee HS, Kim HS, Sun HY, Seung DY. Redox shuttle additives for chemical overcharge protection in lithium ion batteries. Korean J Chem Eng, 2002, 19: 645-652

36 Liu M, Visco SJ, De Jonghe LC. Novel solid redox polymerization electrodes all-solid-state, thin-film, rechargeable lithium batteries. J Electrochem Soc, 1991, 138: 1891-1895

37 Häupler B, Wild A, Schubert US. Carbonyls: powerful organic materials for secondary batteries. Adv Energy Mater, 2015, 5: 1402034

Acknowledgements This work was financially supported by AcRF Tier 1 (RG 13/15 and RG133/14) and Tier 2 (ARC 2/13) from the Ministry of Education, Singapore, and the Campus for Research Excellence and Technological Enterprise (CREATE) program (Nanomaterials for Energy and Water Management) from the National Research Foundation (NRF), Singapore.

Author contributions Xie $\mathrm{J}$ wrote the paper. Xie $\mathrm{J}$ and Wang $\mathrm{Z}$ conceived the experiments. Xie J, Gu P and Zhao Y collected the data and analyzed the results. $\mathrm{Xu} \mathrm{ZJ}$ provided the glovebox for cell assembling and necessary discussions. Zhang Q supervised the project, conceived the experiments, analyzed the results and wrote the paper. All authors contributed to the general discussion.

Conflict of interest The authors declare that they have no conflict of interest.

Supplementary information Experimental details are available in the online version of the paper. 


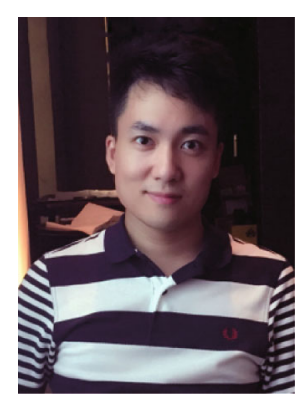

Jian Xie received his BEng degree in materials science and engineering from Nanyang Technological University in Singapore in 2013. After one and a half years of industrial experience as a process engineer, he is currently a PhD candidate in Prof. Qichun Zhang's group, Nanyang Technological University, Singapore. His research focuses on the synthesis and fabrication of polymer electrode materials.

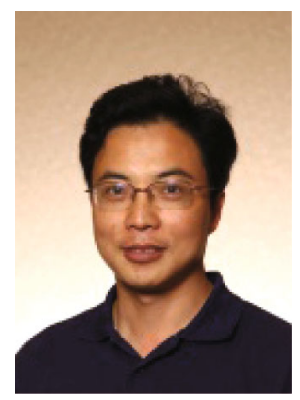

Qichun Zhang obtained his BSc degree at Nanjing University in China in 1992, MSc degree in physical organic chemistry at the Institute of Chemistry, Chinese Academy of Sciences in 1998, MSc in organic chemistry at the University of California, Los Angeles (USA), and completed his PhD in inorganic chemistry at the University of California Riverside (USA) in 2007. Then, he joined Prof. Kanatzidis's group at Northwestern University as a postdoctoral fellow (Oct. 2007-Dec. 2008). Since Jan. 2009, he joined the School of Materials Science and Engineering at Nanyang Technological University (NTU, Singapore) as an assistant professor. On Mar 1st, 2014, he has been promoted to associate professor with tenure and on Dec 1st, 2014, he became an adjunct associate professor at the Division of Chemistry and Biological Chemistry, the School of Physical and Mathematical Sciences, NTU. He has published more than 195 papers and 4 patents (H-index: 38).

\section{基于苯醌结构的新型聚合物电极用于高性能的锂离子电池}

谢健, 王子龙, 顾培洋, 赵毅, 徐梽川, 张其春

摘要 近年来, 设计和合成高性能的锂离子电池用有机化合物电极吸引了许多的关注. 很多研究表明基于苯醌和硫醚结构的聚合物可以同时具 有高比容量和稳定的循环效率. 本研究用一个简单的聚合方法合成了一个新型的梯形聚合物聚 (2,3-二噻烯-1,4-二苯醌) (PDB). 分析发现此聚合 物具有 $1050 \mathrm{mAh} \mathrm{g}^{-1}$ 的初始可逆比容量, 并且在循环一百次之后还保留有 $681 \mathrm{mAh} \mathrm{g}^{-1}$ 的比容量和 $98.4 \%$ 的库伦比效率. 当此聚合物在不同电流 下充放电后并且重新设置回小电流时, 其比容量还可以恢复到之前小电流充放电时的性能, 证明了此聚合物有很好的倍率性能. 进一步大电流 充放电表明此聚合物可以一直持续1000个循环, 再次说明了此聚合物电极的循环稳定性. 